\title{
TETTIGIDEAN NOTES, AND A NEW SPECIES.
}

BY A. P. MORSE, WELLESLEY, MASS.

Among some Tettiginae recently received for study from Mr. Wm. T. Davis I find a male and female of Tettigidea acuta Morse taken on Staten Id. in April. These are the first examples I have seen since the preparation of the original description which was based on specimens in the Scudder collection taken by or secured from Uhler and labeled simply "N. Y." This material contains also two females of Tettigidea lateralis from the same locality, one macropterous, Mar. 2, one micropterous, Oct. 23.

The most interesting part of the collection, however, is a series of 15 specimens of an undescribed form or species of this genus, related to armata Morse, collected at Perth Amboy, N. J., May 31; Jamesburg, N. J., Aug. 31; and Staten Id., N. Y., in April, June, and August. All are brachypterous, the pronotum nearly reaching or slightly passing the hind knees. This form is distinguished from armata, which it most resembles, by the customary lack of a cuspidate point on the front margin of the pronotum, which is for the most part simply obtuse-angulate with the sides straight, slightly sinuate, or shallowly excavate, occasionally showing variations toward a cuspidate condition. The tegmina are relatively short, bluntly rounded or truncate at apex, with the usual white spot exceptionally large, triangular, sometimes covering nearly two-thirds of the exposed distal half of the tegmina. In size, sculpture of surface of pronotum, and form of vertex it is apparently not distinguishable from armata.

I take pleasure in naming this species Tettigidea davisi for its discoverer, in deference to his studies on the orthoptera of the vicinity of New York.

A Note on the Distribution of Bittacomorpha jonesi.- Since describing this species (Psyche, XII, p. 75, 1905) from Mt. Taxoway, N. C., I have collected four specimens, June 18, 1906, along the foot of the Hoosac Mt. at Briggsville, two miles northeast of North Adams, Mass., and one specimen near St. Johnsbury, Vt., June 27, 1906, along a branch of the Passumpsic River. Recently Mr. H. S. Harbeck informs me that he has collected a specimen at Clementon, N. J.

C. W. Johnson. 

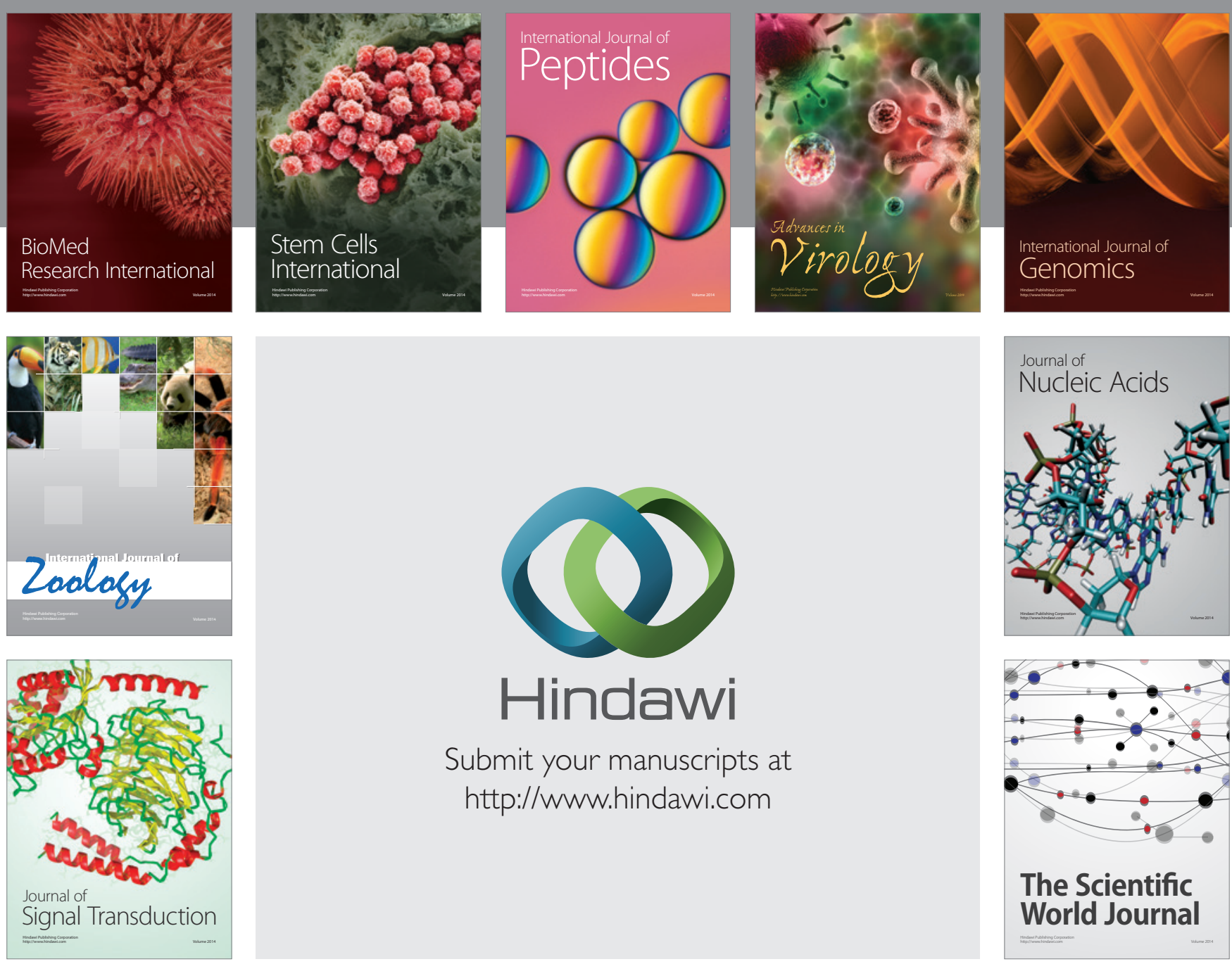

Submit your manuscripts at

http://www.hindawi.com
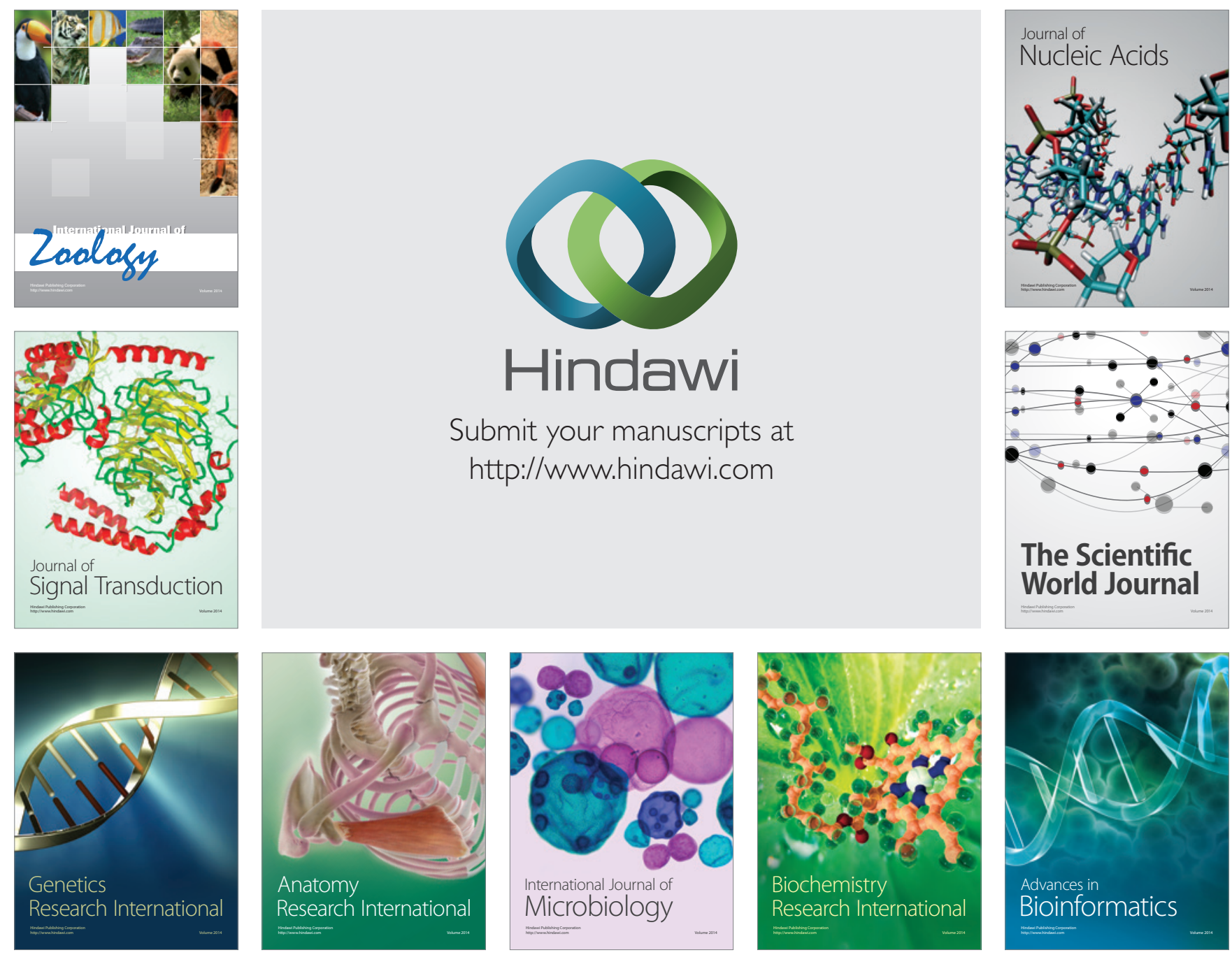

The Scientific World Journal
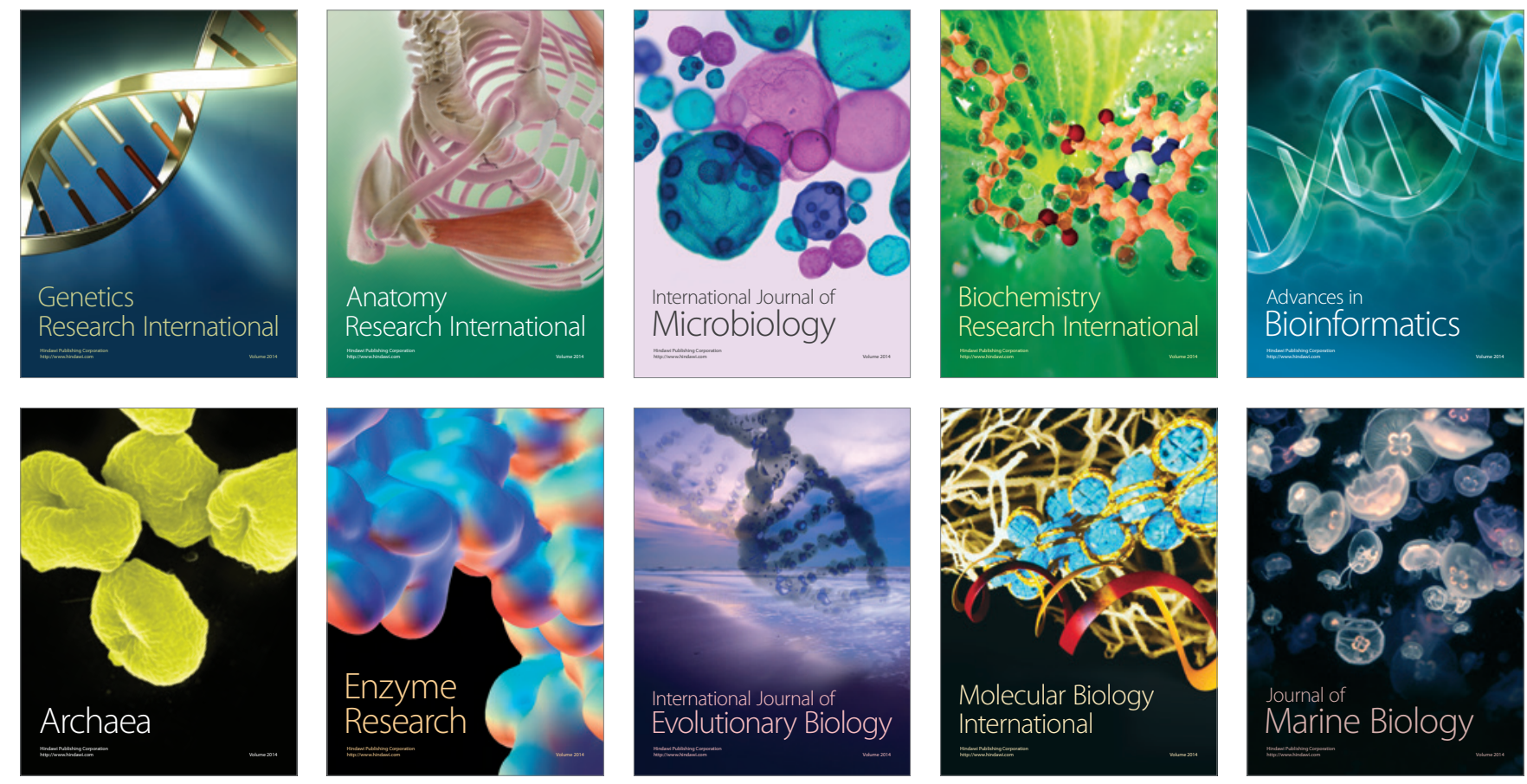